\title{
THE MECHANICAL PROPERTIES OF MODIFIED (HMA) SMIXTURES FOLLOWING SHORT-TERM AND LONG-TERM AGEING
}

\section{Hassan Younes Ahmed}

Assistance Prof., Civil Engineering Department, Faculty of Engineering, Assiut University, Assiut, Egypt

E-mail:Younes@aun,adu,eg.

(Received June 24, 2007 Accepted, August 26, 2007)

Aggregate and asphalt binder provides the main structure skeleton of the hot mix asphalt (HMA). Due to the nature of high inhomogeneity between aggregate and asphalt binder, significant stress and strain concentration occurs at the interface between the two mix components. The asphalt binder is known to stiffen during the mixing and laying-down operations (short term ageing), as well as during the service life of the pavement (long-term ageing). Asphalt modifiers are usually used to improve the asphalt mixtures properties. One of those modifiers is a polymer, which usually used in asphalt mixtures as a binder modifier (wet process). In wet process, polymer particles react with bitumen at high temperatures during the manufacturing stage. Polypropylene $(P P)$ is the representatives of the category, but due to its non-polar nature, it is almost completely immiscible with asphalt binder. Moreover, the high tendency to crystallize further limits the interactions between the asphalt binder and Polypropylene (PP).

This paper presents a novel idea for using a polypropylene $(P P)$ to mitigate the stress and strain concentration between aggregate surface and bitumen layer by introducing an intermediate thin plastic layer between aggregate and asphalt binder as a third layer in HMA. That mediator layer is manufactured by coating of aggregate surface using (PP) before mixing with asphalt, forming Polypropylene treated composite mixtures called "plastiphalt". The percentage of (PP) was about $1.7 \%$ by weight of course aggregate, which represent about $0.60 \%$ by weight of the total bitch. Laboratory aging procedures have been set up to simulate the ageing process through the use of accelerated tests. The two stages of ageing, is the short-term ageing (maximum six hours at $140^{\circ} \mathrm{C}$ at the loose condition to simulate the production to laying period) and long-term ageing ( $24 \mathrm{hrs,}$ $72 \mathrm{hrs}$, and $120 \mathrm{hrs}$ ) at $85^{\circ} \mathrm{C}$, of compacted specimen to simulate mixtures at different durations in service condition. Moisture damage effect through subjected the samples to vacuum water pressure up to $66 \mathrm{~cm}$ mercury with in 5 hours has also conducted. It's found that polypropylene treated composite mixtures significantly improve the mechanical properties. The results demonstrated that the influence of short-term ageing on hardening asphalt is highly significant compared to long-term ageing. The short term and long term ageing evaluations, and resistance of moisture damage for 
"plastiphalt" mixtures indicated significant improvement of pavement performance.

KEYWORDS: Hot mix asphalt, Short-term ageing, long-term ageing, Polypropylene (PP), Moisture susceptibility.

\section{INTRODUCTION}

Flexible pavement structure is usually built with several layers; the above layer, usually made by hot mixture asphalt (HMA) which consist of three components, aggregates (or solid materials), asphalt binder (mastic) and air voids. The weight percent ratio of asphalt to solid materials in a mix is typically (4.5 to $5.5 \%$ ) asphalt and (94.5 to 95.5 $\%)$ of aggregates. Therefore, Asphalt and Aggregates are the two main components of an asphalt concrete mix. The interaction between bitumen binder and aggregate particles in a mix plays a major role in the performance of a pavement. Unfortunately, both components have their separate chemical and physical properties. These properties of asphalt and aggregates also affect each other when both are in close contact. Thus, the properties of HMA mixtures are mainly dependent on the interfacial bonding strength between asphalt binder and aggregates. It was found that the stress concentrates more at large particles than at small particles [1]. Excess stress and strain concentration will be induced at the interface between the aggregate and asphalt cement two phases, which is disadvantageous to HMA performance [2]. An intermediate layer between aggregate surface and asphalt binder would significantly increase the composite elastic modulus (stiffness) and reduce the stress and strain concentration [3].

Mainly the asphalt components have the responsibility of the pavement layers to resist failure. One of the reasons for the deterioration of asphalt concrete mix with time is aging. Hardening of the asphalt in service may be expected to influence the asphalt aggregate bond because of the changes in chemical composition that occur during aging. The changes caused by oxidative aging can change the nature of the chemistry of the interface. The compounds typically produced during aging are sulfoxides, carboxylic acids, and ketones [4]. Both of them have a high affinity for the aggregate surface. Excessive age hardening can result in brittle bitumen with significantly reduced flow capabilities, reducing the ability of the bituminous mixture to support the traffic and thermally induced stresses and strains, which contribute to various forms of cracking in the asphalt mixture $[5,6]$.

To study the ageing effect on the laboratory-fabricated specimen to simulate field condition, it is important to account how the asphalt mixture ages in asphalt plant and also in the service life. Briefly, the mixture ages as it goes through the plant in production stage, and during transportation, until it cools down to normal temperature (short term ageing). Ageing also continues at a slower rate throughout the service life of the pavement (long term ageing), where reaction proceeds at a higher rate in hot climates or during the summer months when temperatures are higher as it prevail in Upper Egypt.

Previous work $[7,8,9]$ considering short-term and long-term oven ageing were adopted. They reported that, a 2-day oven-ageing regime at temperature $85^{\circ} \mathrm{C}$ appears representative of up to 5 years in service and an ageing period of 4 or 5 days is used to simulate the ageing process for 10 -year-old projects. In addition, it is reported that this 
test method appeared to be sensitive to the volumetric proportion of bitumen and air void contents and could be used for comparative purpose [10].

The other cause of premature pavement failure is the moisture damage of the asphalt concrete layer. Moisture damage in the asphalt concrete pavement occurs due to the loss of adhesion (stripping) or loss of cohesion (i.e. softening of asphalt that weakens the bond between asphalt and aggregate) [11]. The stripping of asphalt from the aggregates results in the reduction of strength of asphalt concrete mixture.

The available methods of strengthen the adhesion between aggregate surface and bitumen film lie in two categories: either by treating aggregate surfaces or by reducing the surface tension of the bitumen binder by suitable adhesion - improving agents. If one would be able to introduce a third material, between asphalt cement and aggregate, to form an intermediate layer between the asphalt cement and aggregate, the stress concentration should be mitigated and subsequently, the performance of HMA could be appreciably enhanced. Microstructural analyses of layered system indicated that the three-layered composite HMA mixture would potentially improve the performance of asphalt mixture by reducing the stress and strain concentration [12].

Asphalt modifiers are usually used to improve the asphalt pavement properties. One of those modifiers is polymers which usually used in asphalt mixtures as a binder modifier (wet process). In wet, polymer particles react with bitumen at high temperatures during the manufacturing stage. Polypropylene (PP) is the representatives of the category, but due to its non-polar nature, it is almost completely immiscible with asphalt. Moreover, the high tendency to crystallize further limits the interactions between the asphalt and polymer. So, the main objective of this research is to provide new technique in using a polypropylene (PP) polymer by introducing it as a thin layer between aggregate surface and asphalt binder in HMA mixture by coated a thin layer film on the surface of coarse aggregate forming asphalt mixture named "plastiphalt" or what is called three layered hot mix asphalt. The intermediate layer would decrease the problem of stress and strain concentration between aggregate particle surface and bitumen layer.

Laboratory experiments have been conducted to find out the effect of polypropylene treated composite mixtures (plastiphalt) on the mechanical properties of asphalt mixture compared with Traditional one. Also, the mixtures were subjected to two stages of ageing, short-term ageing, where samples are placed in a forced draft oven (maximum six hours at $140^{\circ} \mathrm{C}$ at its loose condition to simulate the production to laying period) and long-term ageing, where samples are placed in a forced draft oven for (24 hrs, $72 \mathrm{hrs}$, and $120 \mathrm{hrs}$ ) at $85^{\circ} \mathrm{C}$ of compacted specimen to simulate mixtures at different duration in service condition. Moisture damage effect through subjected the samples to vacuum water pressure up to $66 \mathrm{~cm}$ mercury within 5 hours has also conducted. The laboratory evaluations of the performance of HMA mixtures were considered utilizing Marshall Stability, Marshall Quotient (MQ), Indirect Tensile Strength (ITS), Unconfined Compression Strength (UCS), and moisture susceptibility test of indirect tensile strength ratio (ITSR). 


\section{MATERIALS AND SPECIMEN PREPARATION}

\subsection{Aggregates}

Coarse aggregate and fine aggregate with properties shown in Table (1) were used in the preparation of the asphalt concrete mixtures. Limestone was used as mineral filler. The selected gradation of aggregate incorporated in all asphalt concrete specimens confirms to the mid point of the standard 4-c aggregate gradation specified in the Egyptian highway standard specifications. Their used aggregate gradations are presented in Table (2).

Table (1): Properties of coarse and fine aggregate

\begin{tabular}{||l|l|l||}
\hline \hline Properties & Test method & Value \\
\hline Coarse aggregate & & natural \\
\hline L.A. abrasion (\%) & ASTM C-131 & 13.0 \\
\hline Water absorption (\%) & ASTM C-127 & 0.86 \\
\hline Specific gravity g/cm3 & ASTM C-127 & 2.69 \\
\hline Fine aggregate & Non-plastic \\
\hline Plasticity index & & 2.54 \\
\hline Specific gravity g/cm & \\
\hline Water Absorption $(\%)$ & ASTM C-128 & 1.26 \\
\hline
\end{tabular}

Table (2): Selected mix gradation.

\begin{tabular}{||c|c|c||}
\hline \multirow{2}{*}{ Sieve } & \multicolumn{2}{|c|}{ \% Passing } \\
\cline { 2 - 3 } & Used gradation & $\begin{array}{l}\text { Gradation limits [Egyptian } \\
\text { Specs. (4 C)] }\end{array}$ \\
\hline 1 & 100 & 100 \\
\hline $3 / 4$ & 100 & $80-100$ \\
\hline $3 / 8$ & 79 & $60-80$ \\
\hline $3 / 16$ & 50 & $48-65$ \\
\hline $\mathrm{N} 0.10$ & 45 & $35-50$ \\
\hline $\mathrm{N} 0.30$ & 24 & $19-30$ \\
\hline 50 & 22 & $13-23$ \\
\hline 100 & 9 & $7-15$ \\
\hline 200 & 5 & $3-8$ \\
\hline
\end{tabular}

\subsection{Asphalt binder}

Asphalt binder 60/70 supplied by Suez Bitumen Supply Company was used within this research. The used asphalt binder was subjected to a series of standard laboratory tests to determine its physical properties. Results of those tests are shown in Table (3). 
Table (3): Properties of used asphalt binder

\begin{tabular}{||l|c||}
\hline \multicolumn{1}{|c|}{ Test } & Results \\
\hline Penetration at $25 \mathrm{C}^{\mathrm{O}}$ & 68 \\
\hline Kinematics Viscosity (centistokes at135 $\mathrm{C}^{\circ}$ ) & 430 \\
\hline Ring and Ball softening Point & $51.5 \mathrm{C}^{\mathrm{o}}$ \\
\hline Specific gravity & $1.034 \mathrm{gm} / \mathrm{cm}^{3}$ \\
\hline Flash Point & $275 \mathrm{C}^{\mathrm{O}}$ \\
\hline
\end{tabular}

\subsection{Polypropylene (PP).}

Polypropylene (PP) is a linear hydrocarbon polymer, its Semi-rigid, good chemical resistance, tough, good fatigue resistance, integral hinge property, and good heat resistance. Polypropylene-based materials are widely used in automotive applications due to their excellent balance of properties and low cost. In this research, the granulated Polypropylene passed from sieve (No.4) and retained on sieve (No.8) was imported by the United International Trade Co. Geza City. The used Polypropylene is subjected to a series of standard laboratory tests to determine its physical properties. Results of those tests are shown in Table (4).

Table (4): Properties of used polypropylene

\begin{tabular}{||l|c||}
\hline \multicolumn{1}{|c|}{ Test } & Results \\
\hline Water absorption, 24 & 0.01 \\
\hline Elongation (\%) & 20 \\
\hline Specific Gravity: & 0.90 \\
\hline Tensile Strength (MPa) & 45 \\
\hline Flexural modulus (MPa) & 1820 \\
\hline Processing Temperature $\left({ }^{\circ} \mathrm{C}\right)$ & 230 \\
\hline Melting Temperature $\left({ }^{\circ} \mathrm{C}\right)$ & 200 \\
\hline
\end{tabular}

\subsection{Preparation of Samples:}

The stress concentrates in the asphalt mixture are more at large particles than that at small particles [1]. So in this work only coarse aggregate simulating sieve $3 / 4,3 / 8$, and $3 / 16$ are coated with polypropylene. The fine aggregates are used without any coating with polypropylene (PP).

Coarse limestone aggregates were coated with thin layer of polypropylene prior to mixing with fine aggregates and asphalt binder. The percentage of polypropylene (PP) was about $1.7 \%$ by weight of course aggregate, which represent about $0.60 \%$ by weight of the total bitch. The calculated film thickness of the polypropylene coating was about $2.5 \mu \mathrm{m}$.

During this laboratory experiment, the following technique sequence was used for coating the aggregate surface with thin layer film of polypropylene:

1. Aggregate was heated in an oven at a temperature of at least $150{ }^{\circ} \mathrm{C}$.

2. The stainless steel container used for mixing was cleaned and aggregate with temperature $150{ }^{\circ} \mathrm{C}$ as put in it. 
3. The asphalt mixer was started, and the prepared amount of crushed polypropylene was added gradually to the container while heating up to $230{ }^{\circ} \mathrm{C}$. The mixing was continued for at least $5 \mathrm{~min}$, and until completely coating was obtained.

4. At the end of the mixing operation, the coated aggregate was lift to cool.

5. Then the polypropylene treated composite mixtures used to prepare Marshall specimens forming what is named "plastiphalt".

In real field operation for plant mixing, practically and applicable method should be employed to coat the aggregate in a safe and economical way. Fig.(1) presents the coating aggregates with polypropylene.

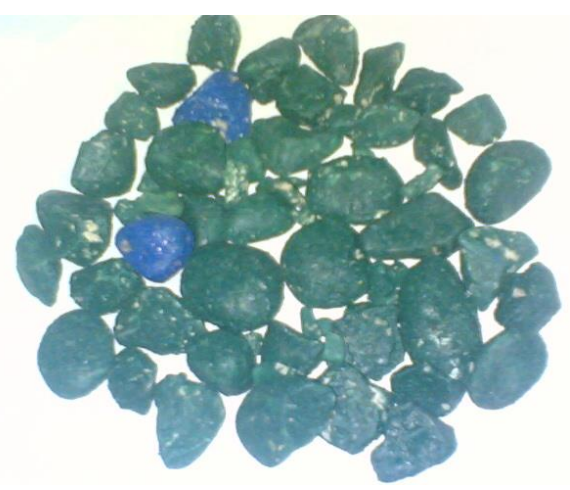

Figure (1): Coated aggregates with polypropylene

\subsection{Mixture Design}

Marshall Method (ASTM D1559) was used for determining optimal bitumen content for traditional. Specimens of $63.5 \mathrm{~mm}$ height and $100 \mathrm{~mm}$ diameter were compacted by applying 75 blows with the compaction hammer for each face (two faces). After compaction, the mould was removed from the base-plate; the specimen was cured for $4 \mathrm{~h}$ in the mould at room temperature before extruding it by means of an extrusion jack. Three identical samples were produced for all alternatives. Bitumen range region was regulated according to the bitumen demand for each mixture. The optimum asphalt content was determined it was $5.2 \%$ of the total weight of mixture. No separate mix design was performed for the composite mixtures containing polypropylene interlayer. The amount of polypropylene coating the coarse aggregate was considered as part of the total asphalt content.

\section{MIXTURE PERFORMANCE TESTS}

Stability of an HMA pavement, is the most important property of the bitumen mixture, its the ability to resist shoving and rutting under traffic. Therefore, stability should be high enough to carry traffic load, but not higher than the traffic conditions required to avoid cracking. The lack of stability in an asphalt mixture causes flow of the road surface. The flow may be regarded as an opposite property to the stability, determining 
the reversible behavior of the wearing course under traffic loads and affecting plastic and elastic properties of the asphalt concrete [13].

The Marshall Quotient (MQ), (Stability to flow) calculated and thereby representing an approximation of the ratio of load to deformation under the particular conditions of the test, can be used as a measure of the material's resistance to permanent deformation in service $[14,15]$.

Tests used to assess the resistance of bituminous mixes to flow, rutting or cracking are mainly the Marshall Test, the Indirect Tensile Strength Test, and Unconfined Compression Strength Test. These tests provide qualitative evidence to conclusions from field observations. Nevertheless, these tests are useful to compare alternative mix compositions from a qualitative point of view; in addition, determination tests provide access to some intrinsic mix properties, which can be used in the theoretical and semi theoretical performance models [16].

\subsection{Marshall Test}

The Marshall Stability test (ASTM Designation: D 1559-82), is used in highway engineering for both mix design and evaluation. Although Marshall method is essentially empirical, it is useful in comparing mixtures under specific conditions. Therefore, it was selected within this research to study the effect of polypropylene treated composite mixtures on the mechanical properties of hot mix asphalt.

Optimum asphalt content was determined it was $5.2 \%$. That value was chosen for all mixtures so that the amount of binder would not confound the analysis of the test data. The Marshall stability results for traditional and plastiphalt mixtures for non ageing and for different aging process are found and discussed.

\subsection{Marshall Quotient}

Marshall Quotient (MQ) is an indicator of the resistance against the deformation of the asphalt concrete. A higher value of MQ indicates a stiffer mixture and, hence, indicates that the mixture is likely more resistant to rutting and shoving, but crack hazardous may be occurring. The value of MQ is calculated as follows.

$$
\mathrm{MQ}=\frac{M_{S}}{M_{F}}
$$

Where:

MQ = Marshall Quotient.

$\mathrm{M}_{\mathrm{S}}=$ Marshall Stability.

$\mathrm{M}_{\mathrm{F}}=$ Marshall Flow.

\subsection{Indirect Tensile Strength Test (ITS)}

The indirect tensile strength test is used to determine the tensile strength and strain of the asphalt concrete which can be further related to the cracking properties of the pavement. This test is summarized in applying compressive loads along a diametrical 
plane through two opposite loading strips Figure (2). This type of loading produces a relatively uniform tensile stress, which acts perpendicular to the applied load plane, and the specimen usually fails by splitting along the loaded plane.

Test is the simple and Marshall Specimens was used. Surface irregularities do not seriously affect the results and the coefficient of the variation of the test results is low. This test was conducted at $25^{\circ} \mathrm{C}$ on briquettes both on traditional mixture and polypropylene treated composite mixtures (plastiphalt). Test specimen was loaded at (0.05 in./min) deformation rate.

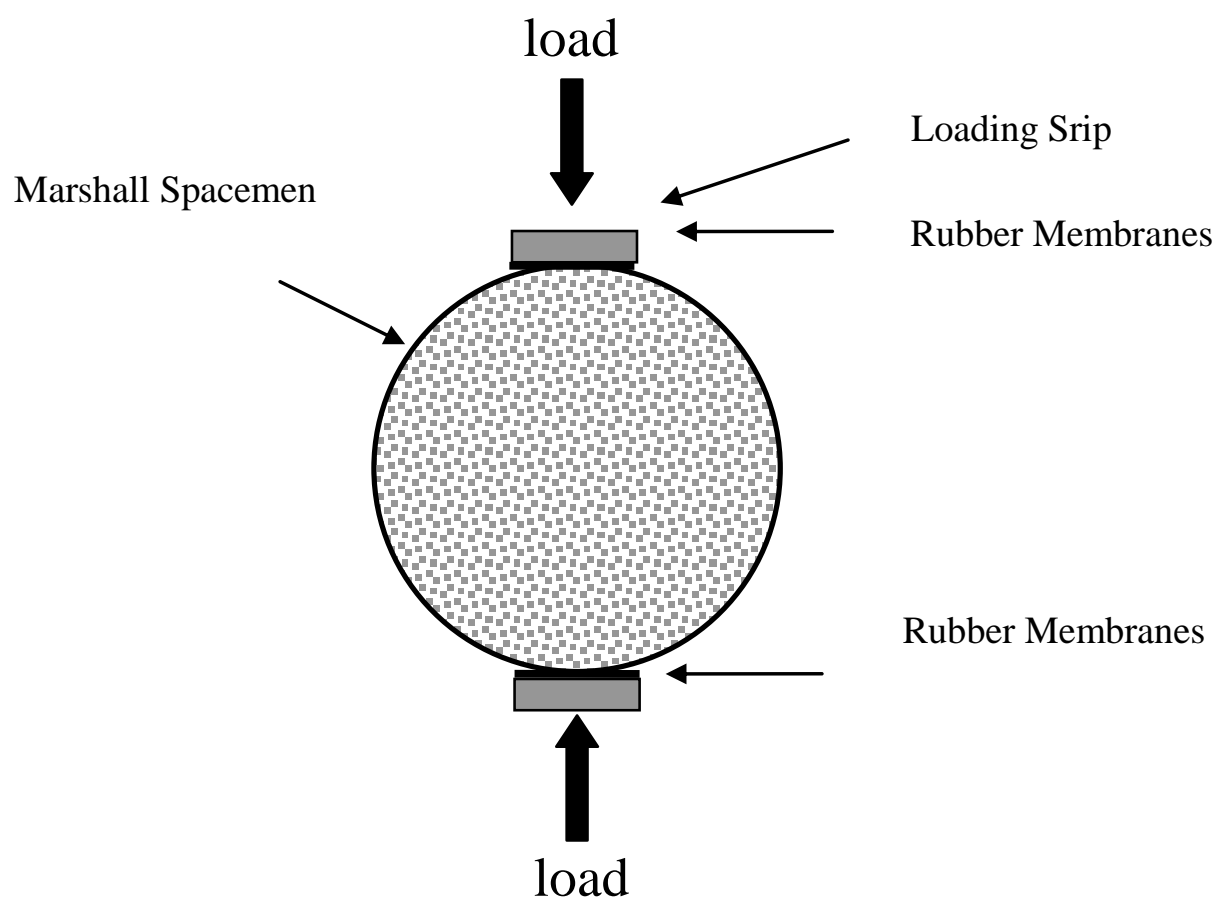

Figure (2): Indirect tension test

The load and deformations were continuously recorded and indirect tensile strength and strain were computed as follows:

$$
\sigma_{t}=\frac{2 P}{\pi D H}
$$

Where:

$\sigma_{t}=$ Tensile strength.

$\mathrm{P}=$ Load.

$\mathrm{D}=$ Diameter of specimen.

$\mathrm{H}=$ Thickness of the specimen.

\section{3-1 Moisture Suscapility Test for Asphalt Pavement Mixtures}

Accelerated moisture damage program was established on the studied mixtures to 
simulate the effect of moisture damage on it. Tripical Marshall specimens from the two studied mixtures were vacuum saturated in water at a vacuum of $660 \mathrm{~mm}$ of mercury $(\mathrm{Hg})$ at conditioning period of 5 hours at a controlled temperature of $\left(25 \pm 1.0{ }^{\circ} \mathrm{C}\right)$. Indirect tensile strength tests were performed on moisture conditioned samples. The results were compared with those for unconditioned ones.

All specimens are tested for indirect tensile strength (ITS) at $25{ }^{0} \mathrm{C}$. This conditioning reflects field performance up to 4 years [17]. The indirect tensile strength (ITS) of the conditioned specimens is compared to the traditional specimens in order to determine the tensile strength ratio (TSR). The indirect tensile strength ratio (TSR) is calculated specimens as follows:

$$
I T S R=\frac{S_{2}}{S_{1}}
$$

Where:

ITSR is indirect tensile strength ratio.

$\mathrm{S}_{1} \quad$ is the Average indirect tensile strength of unconditioned specimen.

$\mathrm{S}_{2} \quad$ is the Average indirect tensile strength of conditioned specimen.

It's recommended that the minimum ITSR of 0.7 for bituminous mixture based on their laboratory and field study [18]; this recommendation was adopted by AASHTO $\mathrm{T} 283$ [19]. It has been argued that the Lottman procedures are too severe because the vacuum saturated can develop internal water pressure. However, Parker and Gharaybeh [20] generally found a good correlation between the laboratory and field results.

\subsection{Compression Strength Test.}

The Unconfined compression strength test was performed by using Universal Standard Compression Testing Machine. To accurately apply axial compressive loading on the specimen, two end surfaces must be kept parallel by spreading a layer of high strength plaster.

Marshall Specimens were used in this test. The spacemen groups were subjected to compression strength test at $25{ }^{\circ} \mathrm{C}$. The load and deformations were continuously recorded and the average unconfined compressive strength for various mixtures is calculated based on Equation (4)

$$
\sigma_{c}=\frac{4 P_{\max }}{\pi D^{2}}
$$

Where:-

$\sigma_{c} \quad$ is the Unconfined Compressive Strength.

$\mathrm{P}_{\max }$ is the maximum applied compressive load and,

$\mathrm{D} \quad$ is the diameter of the specimen.

\section{5- Laboratory Ageing Tests}

\subsubsection{Short-term Ageing.}

In this study, the hardening of asphalt pavement in plant during production stage, and during transportation and spreading, until it cools down to normal temperature are investigated. This requires loose mixtures, prior to compaction, to be aged in a forced 
draft oven at a temperature $140{ }^{\circ} \mathrm{C}$ as a desired compaction temperature, was chosen for both traditional and polypropylene treated asphalt mixtures. This have been dune by placed asphalt mixtures on a shallow tray and aged in a force-draft oven for 5 hours. The asphalt mixtures subjected to short term ageing is summarized as (C6), while the asphalt mixtures that not-conditioning (original one) is summarized as (C0).

\subsubsection{Long-term Ageing.}

To simulate the ageing processing in the field of the two asphalt mixtures under investigation (traditional and polypropylene treated asphalt mixtures), compacted mixtures which subjected to short-term conditioning $\left(\mathrm{C}_{24 \mathrm{hr}}, \mathrm{C}_{72} \mathrm{hr}, \mathrm{C} 6_{120 \mathrm{hr}}\right)$, and for that without short-term conditioning $\left(\mathrm{C}_{24} \mathrm{hr}, \mathrm{C}_{72} \mathrm{hr}, \mathrm{C}_{120} \mathrm{hr}\right)$ are placed in a forced draft oven at $85^{\circ} \mathrm{C}$ for different curing time.

Three different curing times were considered in this study

1 - Early stage ageing $\left(\mathrm{C}_{24 \mathrm{hr}}\right) \quad 24 \mathrm{hrs}$ (one days),

2 - Medium stage ageing $\left(\mathrm{C}_{72 \mathrm{hr}}\right) \quad 72 \mathrm{hrs}$ (3 days), and

3 - Later stage ageing $\left(\mathrm{C}_{120 \mathrm{hr}}\right) \quad 120$ hours (5 days).

At the end of the ageing periods, the oven is switched off and left to cool to room temperature before removing the specimens. The specimens are not tested until at least 24 hours after removal from the oven.

\section{RESULTS AND DISCUSSION}

The flow chart Fig (3) is summarized the Marshall specimens that subjected to different types of conditioning (original, short term ageing, long term ageing, and short term ageing followed by long term ageing ) for both traditional and plastiphalt mixtures. All specimens are subjected to Marshall test, Indirect tension test, and unconfined compression test. Water susceptibility, cracking resistance of both traditional and plastiphalt is also examined and found. Tripical specimens for each case are tested and the mean value of results is considered for each test type.

\subsection{Marshall Stability Results}

The average Marshall stability values for the traditional and polypropylene treated composite mixtures (plastiphalt) are presented in Table (5). For non-conditioning asphalt mixtures $(\mathrm{C} 0)$, it's found that the Marshall stability value of plastiphalt mixture is higher with about $38 \%$ than that of traditional one. This may be due to the higher adhesion and cohesion that created between bitumen and polypropylene layer and consequently between aggregate surface and coating layer. Also polypropylene play as a sandwich layer which reduce the significant stress and strain concentration that occurs at the interface between the bitumen and aggregate. 


\section{Asphalt Pavement Mixture}

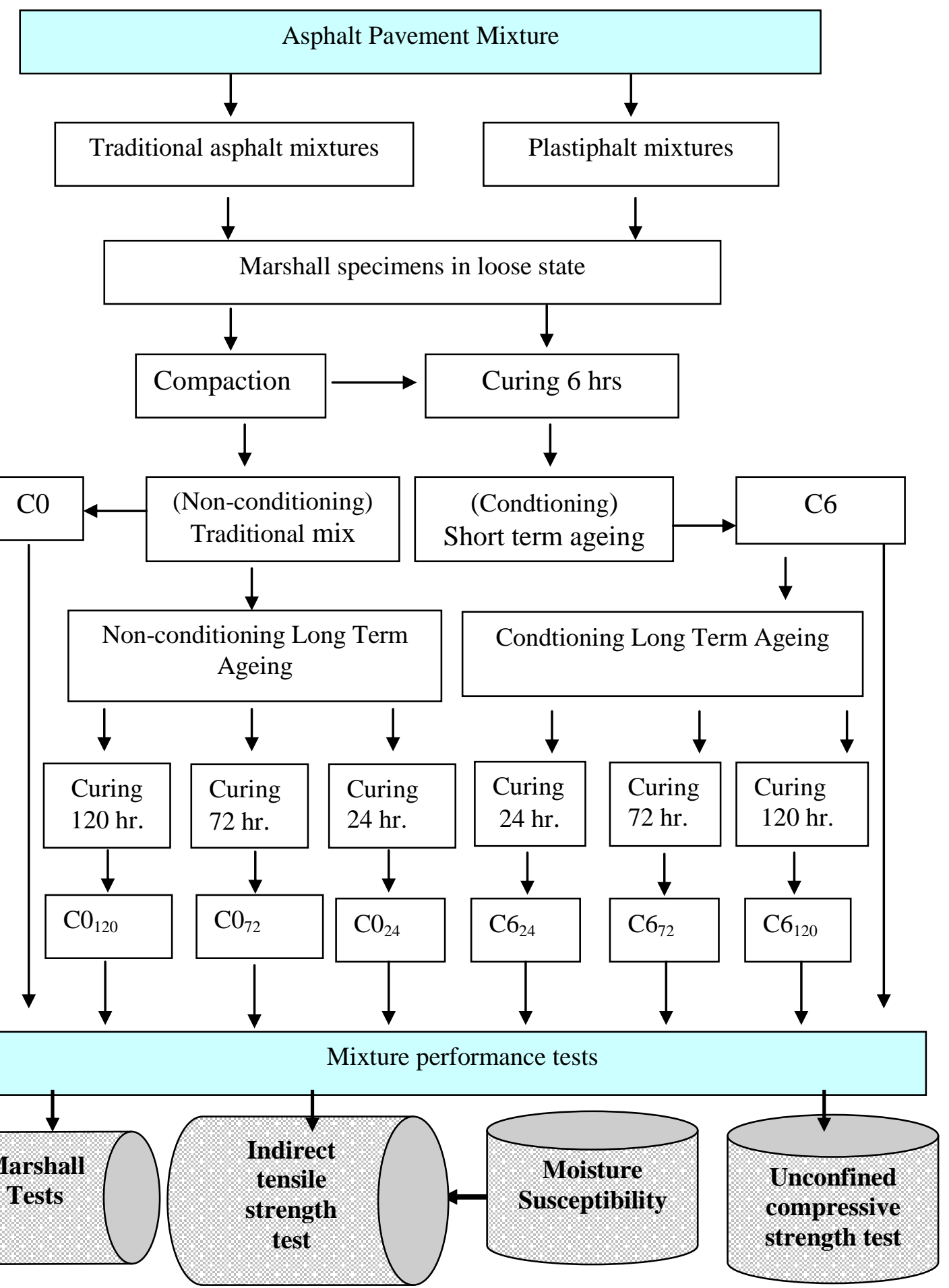

Fig. ( 3 ) : Flow chart for different conditioning cases and different tests for Marshall specimens 


\section{1-1 Short - term and Long - term Ageing.}

Table ( 5 ) and figs $(4,5)$ show that the relative effect of short-term conditioning (C6) is significantly higher compared with long-term ageing which points towards the importance of the mixing, transportation and laying period on mixture's ageing.

Results show that the rate of long-term ageing of asphalt mixtures is higher in early stage compared with late one. These conclude that the properties of asphalt mixture must be considered in pavement design after early stage suggested the first year of pavement age.

It is also found that in all cases of long term ageing process, $\left(\mathrm{CO}_{24} \mathrm{hr}, \mathrm{C}_{72} \mathrm{hr}\right.$, $\left.\mathrm{C}_{120 \mathrm{hr}}\right)$ and short term ageing followed by long-term ageing process $\left(\mathrm{C6}_{24 \mathrm{hr}}, \mathrm{C6}_{72 \mathrm{hr}}\right.$, $\left.\mathrm{C}_{120 \mathrm{hr}}\right)$ the relative increment in the Marshall stability values for traditional mix are higher comparing with that for plastiphalt. This meaning that the asphalt mixtures treated with polypropylene was low harden during ageing process compared with traditional one. This may be attributed to the polypropylene layer has minimize the effect of ageing of bitumen due to its plastic properties and its higher resistance for temperature compared with bitumen material.

Table (5): Marshall stability results for short and long-term aged for traditional and plastiphalt mixtures

\begin{tabular}{||c|c|c|l|l|l|l|l|l||}
\hline \hline \multirow{3}{*}{$\begin{array}{c}\text { Mixture } \\
\text { type }\end{array}$} & \multicolumn{7}{|c||}{ Average values of Marshall stability value in (kN) } \\
\cline { 2 - 9 } & Short term & \multicolumn{6}{|c|}{ Long term } \\
\cline { 2 - 9 } & $\mathrm{C} 0$ & $\mathrm{C} 6$ & $\mathrm{C}_{24} \mathrm{hr}$ & $\mathrm{C}_{72} \mathrm{hr}$ & $\mathrm{C} 0_{120 \mathrm{hr}}$ & $\mathrm{C}_{24} \mathrm{hr}$ & $\mathrm{C}_{72} \mathrm{hr}$ & $\mathrm{C}_{120} \mathrm{hr}$ \\
\hline Traditional & 6.2 & 8.35 & 8.13 & 8.64 & 8.815 & 8.85 & 9.4 & 9.55 \\
\hline Plastiphalt & 6.84 & 8.56 & 8.32 & 8.75 & 8.9 & 9 & 9.5 & 9.6 \\
\hline \hline
\end{tabular}

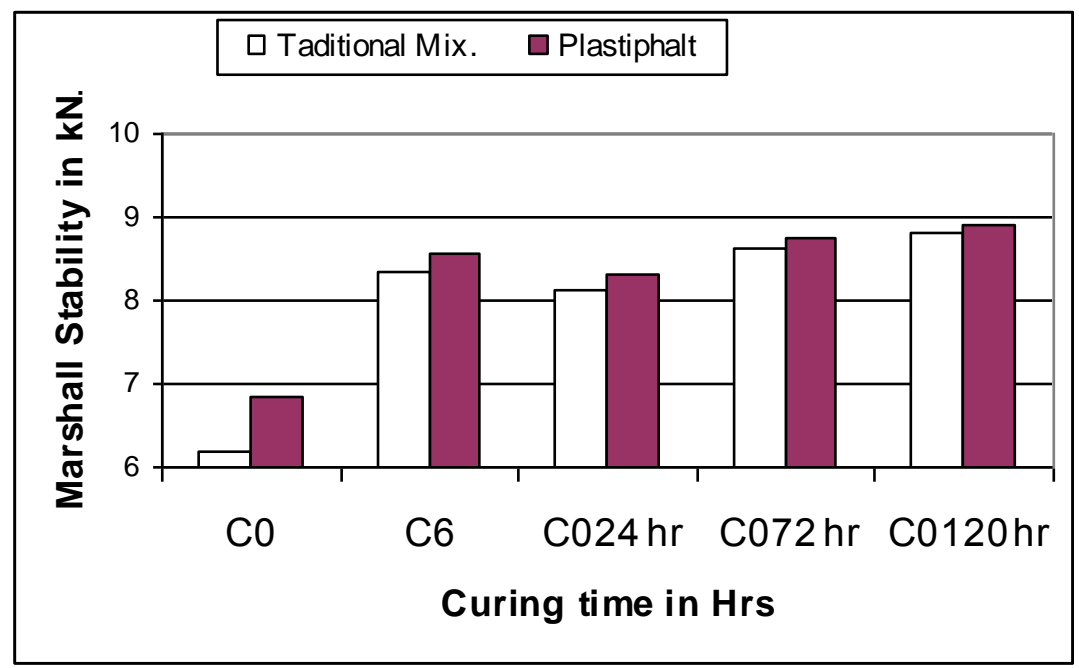

Fig (4): Marshall stability, versus curing time for samples subjected to short term and long term ageing. 


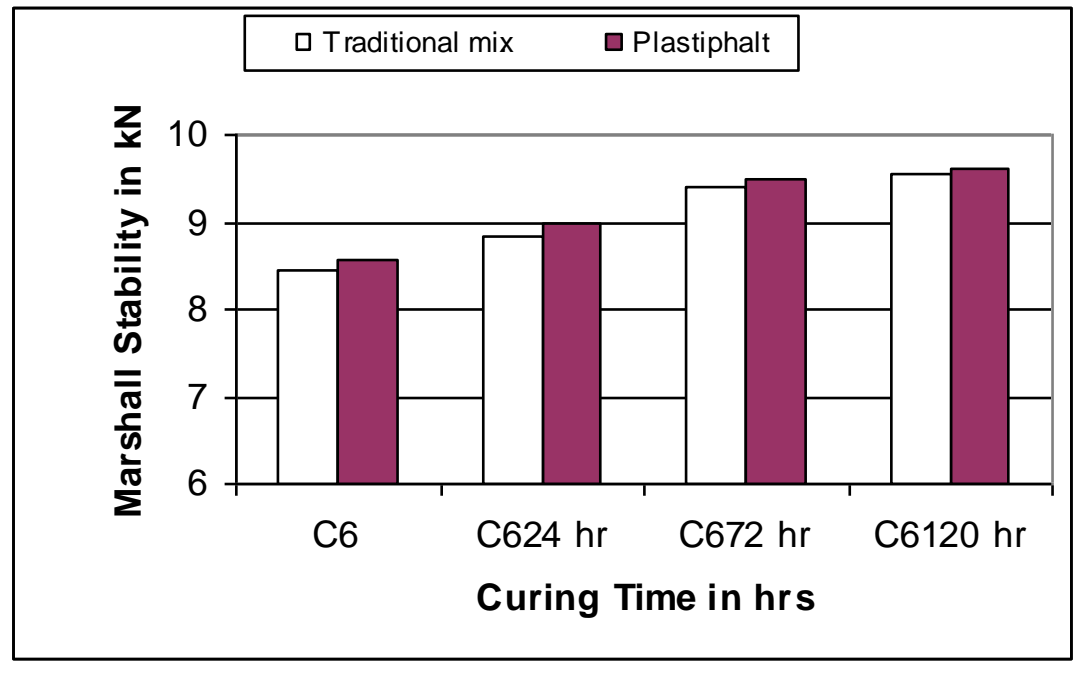

Fig (5): Marshall stability, versus curing time for samples subjected to short term ageing followed by long term ageing.

\subsection{Marshall Quotient Results}

Since Marshall Quotient (MQ) is an indicator of the resistance against the deformation of the asphalt mixture, MQ values are calculated to evaluate the resistance of the deformation of the polypropylene treated asphalt mixture (plastiphalt) compared with traditional one.

Table (7) shows that the Marshal Quotient of plastiphalt mixture is higher with about $18 \%$ than that of traditional mixture for non-conditioning asphalt mixtures $(\mathrm{C} 0)$. This may be due to the high adhesion between polypropylene layer and aggregate surface and also the best merging between bitumen material and polypropylene layer.

\section{2-1 Short-term and Long-term Ageing}

The effect of both short-term and long-term ageing on the value of Marshall Quotient for both traditional and plastiphalt mixtures is presented in Table (7) Fig. (6,7), The results were calculated to observe the change in Quotient in short term ageing C6, and both long terms ageing conditioned and non conditioned specimens for different asphalt mixtures.

Results indicated that the rate of short term ageing (C6) for plastiphat mixture is relatively low than that for traditional one if Marshall Quotient is considered. This may be attributed to that the polypropylene layer following plastic-bitumen surface interaction may minimize the effect of hardening of bitumen. The relative reduction in the increment of the value of Marshall Quotient considering long-term ageing $\left(\mathrm{CO}_{24} \mathrm{hr}\right.$, $\left.\mathrm{C}_{72} \mathrm{hr}, \mathrm{C}_{120 \mathrm{hr}}\right)$ and short term ageing followed by long-term ageing process $\left(\mathrm{C}_{24} \mathrm{hr}\right.$, $\left.\mathrm{C}_{72} \mathrm{hr}, \mathrm{C}_{120 \mathrm{hr}}\right)$ in asphalt mixture dealt with polypropylene layer concluded that that mixture resist flexural cracking of the asphalt layer. 
Table (7): Marshall Quotient results for short and long-term aged Traditional and plastiphalt mixtures

\begin{tabular}{|l|c|c|r|r|r|r|r|l||}
\hline \multirow{3}{*}{$\begin{array}{l}\text { Mixture } \\
\text { type }\end{array}$} & \multicolumn{7}{|c||}{ Average values of Marshall Quotient results in (KN/mm.) } \\
\cline { 2 - 9 } & \multicolumn{1}{|c|}{ Short term } & \multicolumn{6}{|c||}{ Long term } \\
\cline { 2 - 9 } & $\mathrm{C} 0$ & $\mathrm{C} 6$ & $\mathrm{C}_{24} \mathrm{hr}$ & $\mathrm{C}_{72} \mathrm{hr}$ & $\mathrm{C}_{120} \mathrm{hr}$ & $\mathrm{C}_{24} \mathrm{hr}$ & $\mathrm{C}_{72} \mathrm{hr}$ & $\mathrm{C}_{120 \mathrm{hr}}$ \\
\hline Traditional & 1.631 & 2.54 & 2.49 & 2.90 & 3.100 & 3.45 & 4.34 & 4.40 \\
\hline plastiphalt & 1.923 & 2.62 & 2.59 & 2.95 & 3.019 & 3.50 & 4.26 & 4.29 \\
\hline \hline
\end{tabular}

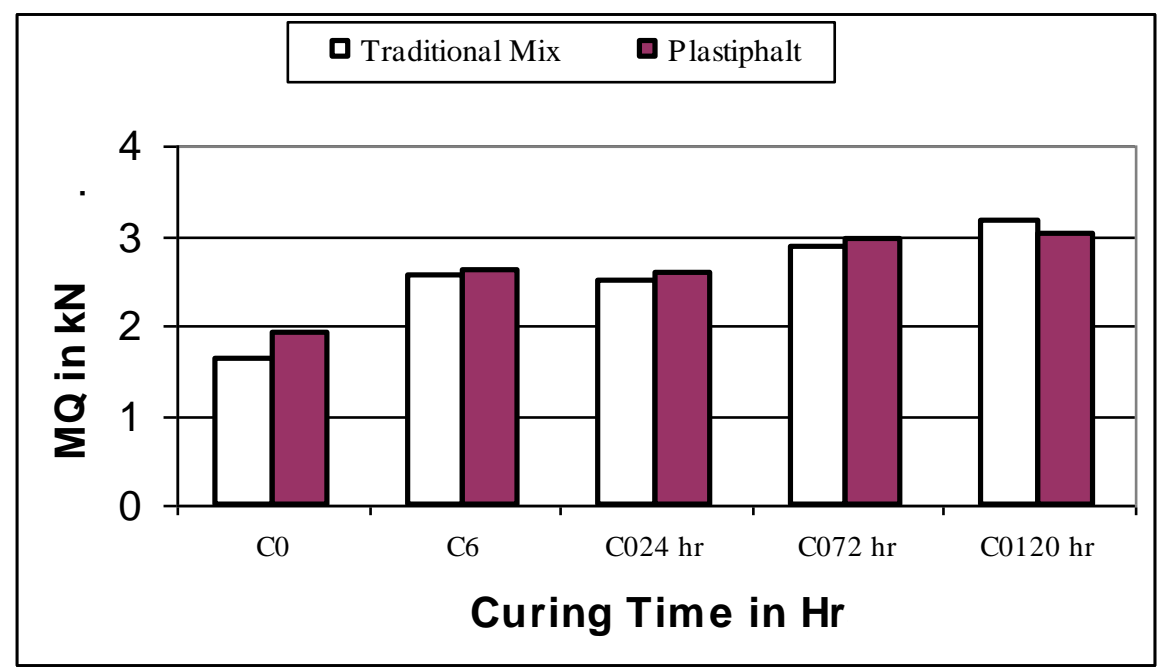

Fig (6): Marshall Quotient, versus curing time for samples subjected to short term and long term ageing.

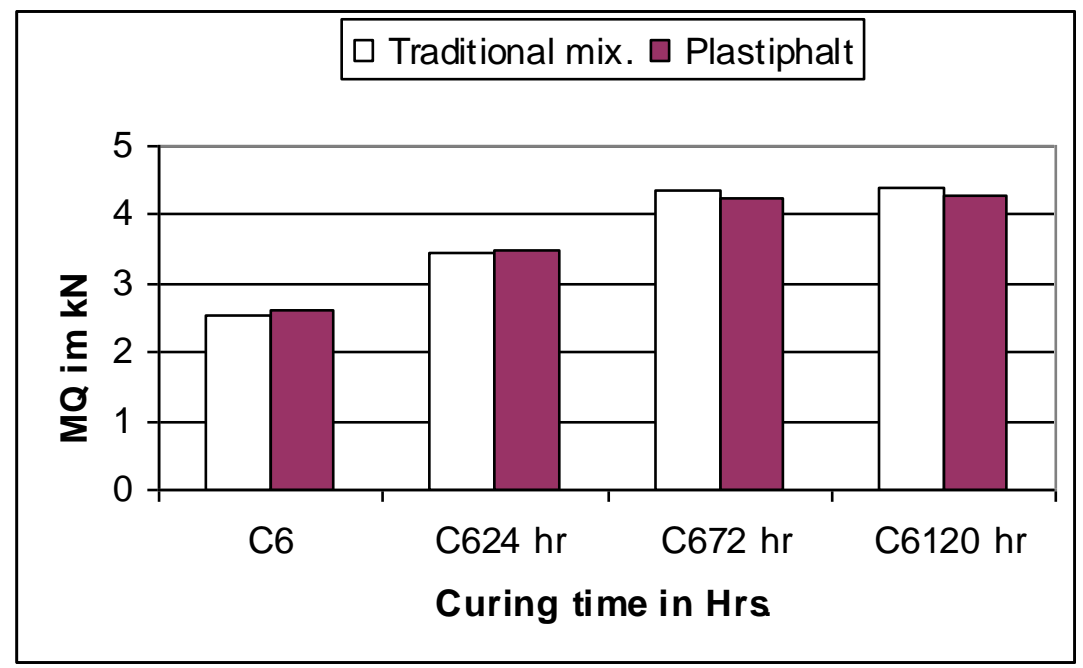

Fig (7): Marshall Quotient, versus curing time for samples subjected to short term ageing followed by long term ageing. 


\subsection{Indirect Tensile Strength (ITS) Results.}

The ITS tests were carried out using Marshall specimens. Fig.(8) present the results of indirect tensile strength test for non-conditioning asphalt mixtures $(\mathrm{C} 0)$. Its found that the polypropylene treated composite mixtures has $37 \%$ higher ITS (averaged 0.52 MPa) than the traditional mixtures (averaged $0.38 \mathrm{MPa}$ ) while the corresponding strain is less with about $13 \%$ for plastiphalt than that of traditional one. This may be due to the high tensile strength of polypropylene which improve both adhesion and cohesion of asphalt mixture. Also polypropylene intermediate layer may be reduce the significant stress and strain concentration that occurs at the interface between the bitumen and aggregate.

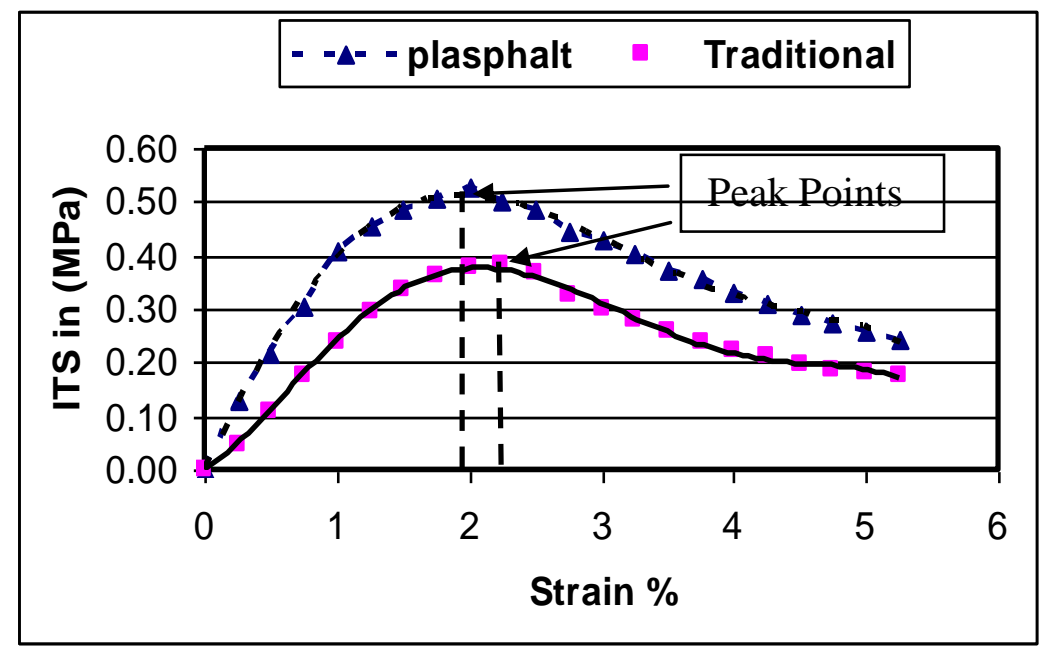

Fig (8): ITS \& strain relationship for traditional and plasiphalt mixtures

\section{3-1. Cracking Resistance}

Materials damage can be usually represented by strain energy density function with the following form [24]:

$$
\frac{\mathrm{d} W}{\mathrm{~d} V}=\int_{0}^{a \mathrm{a}} \sigma_{i j} \mathrm{~d} \varepsilon_{i j},
$$

Where:

$\mathrm{d} W / \mathrm{d} V$ - is the critical strain energy density function represents the area under the stress - strain curve when the stress reaches the peak point;

$\sigma_{i j}$. the stress fraction;

$\varepsilon_{i j}$ - the strain fraction; and

$\varepsilon_{0} \quad$ - is the strain at the peak point of stress as shown in Fig.(8).

The two tension stress-strain functions obtained from polynomial regression are as follows:

For plastiphalt asphalt pavement mixture:

$\sigma=-0.0002 \varepsilon^{5}+0.0034 \varepsilon^{4}-0.0189 \varepsilon^{3}-0.0136 \varepsilon^{2}+0.3038 \varepsilon+0.0005 \ldots(8) R^{2}=0.99$

For traditional asphalt pavement mixture: 
$\sigma=-0.0003 \varepsilon^{5}+0.0057 \varepsilon^{4}-0.0416 \varepsilon^{3}+0.0926 \varepsilon^{2}+0.0883 \varepsilon-0.0002 \ldots(9) \mathrm{R}^{2}=0.99$

Critical tension strain energy density function is obtained after integral calculation, as follows:

For plastiphalt asphalt pavement mixture:

$\mathrm{d} W / \mathrm{d} V \quad \square=-0.0002 \varepsilon^{6} / 6 \square+0.0034 \varepsilon^{5} / 5 \square-0.0189 \varepsilon^{4} / 4 \square-0.0136 \varepsilon^{3} \quad / 3 \square \square+0.3038 \varepsilon^{2}$ $/ 2+0.0005 \varepsilon \ldots . .(10)$

For traditional asphalt pavement mixture:

$\mathrm{d} W / \mathrm{d} V \square=-0.0003 \varepsilon^{6} / 6 \square+0.0057 \varepsilon^{5} / 5 \square-0.0416 \varepsilon^{4} / 4 \square+0.0926 \varepsilon^{3} / 3 \square+0.0883 \varepsilon^{2} / 2-0.0002 \varepsilon$ .......(11)

The values of strains at ultimate stress $\varepsilon_{0}$ of plastiphalt is $1.8 \%$, while for traditional asphalt is $2.1 \%$ as shown in Fig.(8). If we are substituted the values into Eqs. ( 8 ) and ( 9 ), the critical value $\mathrm{d} W / \mathrm{d} V$ is obtained. The critical value of $\mathrm{d} W / \mathrm{d} V$ is 1.30 $\mathrm{kJ} / \mathrm{m}^{3}$ for plastiphalt mixture. but $0.56 \mathrm{~kJ} / \mathrm{m}^{3}$ for traditional one, This appears excellent crack resistance performance because plastiphalt needs more energy than that of traditional mixtures when it reaches material failure situation.

\section{3-2 Short-term and Long-term Ageing:}

The effect of both short-term and long-term ageing on the traditional asphalt mixture and polypropylene treated composite mixtures is presented in Tables (9 and 10) and Figs. ( 9 to 12) including the change in ITS for different ageing conditions and the corresponding strain values. The results show that, the relative effect of short-term conditioning (C6) is significant compared with long-term ageing which points towards the importance of the mixing, transporting and laying period on mixture's ageing.

It is interesting to note that for plastiphalt, the increment in the value of ITS is lower for short term ageing (C6) and long-term ageing $\left(\mathrm{CO}_{24 \mathrm{hr}}, \mathrm{C}_{72} \mathrm{hr}, \mathrm{C}_{120 \mathrm{hr}}\right)$ and short term ageing followed by long-term ageing process $\left(\mathrm{C6}_{24 \mathrm{hr}}, \mathrm{C}_{72} \mathrm{hr}, \mathrm{C}_{120 \mathrm{hr}}\right)$ relative to the traditional asphalt mixtures, while the corresponding strain values are about the same. That may be due to the high interaction between the polypropylene and asphalt layer which play as a plastic layer between aggregate surface and bitumen layer which minimize the effect of hardening of bitumen binder.

Table (9): Indirect tensile stress results for short and long-term aged traditional and plastiphalt mixtures

\begin{tabular}{|c|c|c|c|c|c|c|c|c|}
\hline \multirow{3}{*}{$\begin{array}{c}\text { Mixture } \\
\text { type }\end{array}$} & \multicolumn{8}{|c|}{ Average values of Indirect Tensile Stress in (MPa) } \\
\hline & \multicolumn{2}{|c|}{ Short term } & \multicolumn{6}{|c|}{ Long term ageing after short term ageing. } \\
\hline & $\mathrm{C} 0$ & C6 & $\mathrm{C}$ & $\mathrm{C} 0$ & $\mathrm{CO}$ & $\mathrm{C} 6$ & C6 & $\mathrm{C} 6_{120}$ \\
\hline Traditional & 0.38 & 0.50 & 0.52 & 0.5 & 0.60 & 0.60 & 0.64 & 0.65 \\
\hline plastiphalt & 0.52 & $0 . .58$ & 0.61 & 0.66 & 0.67 & 0.65 & 0.68 & 0.68 \\
\hline
\end{tabular}

The ITS test results of both plastiphalt and traditional samples of nonconditioned and conditioned specimens are given in Table (11) and Fig. (14). To find out the effect of the polypropylene treated composite mixtures on the moisture susceptibility characteristics of hot mix asphalt, the ITS of the conditioned specimens 
was compared to the non-conditioned ones. Indirect tensile strength ratio (ITSR) is determined using Equation (3).

Table 10: Permanent deformation parameters ( $\%$ of strain values) for traditional and plastiphalt asphalt mixtures

\begin{tabular}{|c|c|c|c|c|c|c|c|c|}
\hline \multirow{3}{*}{$\begin{array}{c}\text { Mixture } \\
\text { type }\end{array}$} & \multicolumn{8}{|c|}{ Average values of \% of strain at peack Indirect Tensile Stress ) } \\
\hline & \multicolumn{2}{|c|}{ Short term } & \multicolumn{6}{|c|}{ Long term ageing after short term ageing. } \\
\hline & $\mathrm{C} 0$ & C6 & $\mathrm{CO}_{24 \mathrm{hr}}$ & $\mathrm{C}_{72} \mathrm{ht}$ & $\mathrm{C}_{120 \mathrm{hr}}$ & $\mathrm{C}_{64} \mathrm{hr}$ & $\mathrm{C}_{72 \mathrm{hr}}$ & $\mathrm{C}_{120 \mathrm{~h}} \mathrm{r}$ \\
\hline & 2.25 & 1.75 & 2.00 & 1.75 & 1.5 & 1.25 & 1.0 & 0.75 \\
\hline plastiphalt & 2.00 & 1.75 & 1.75 & 1.75 & 1.5 & 1.25 & 1.0 & 0.75 \\
\hline
\end{tabular}

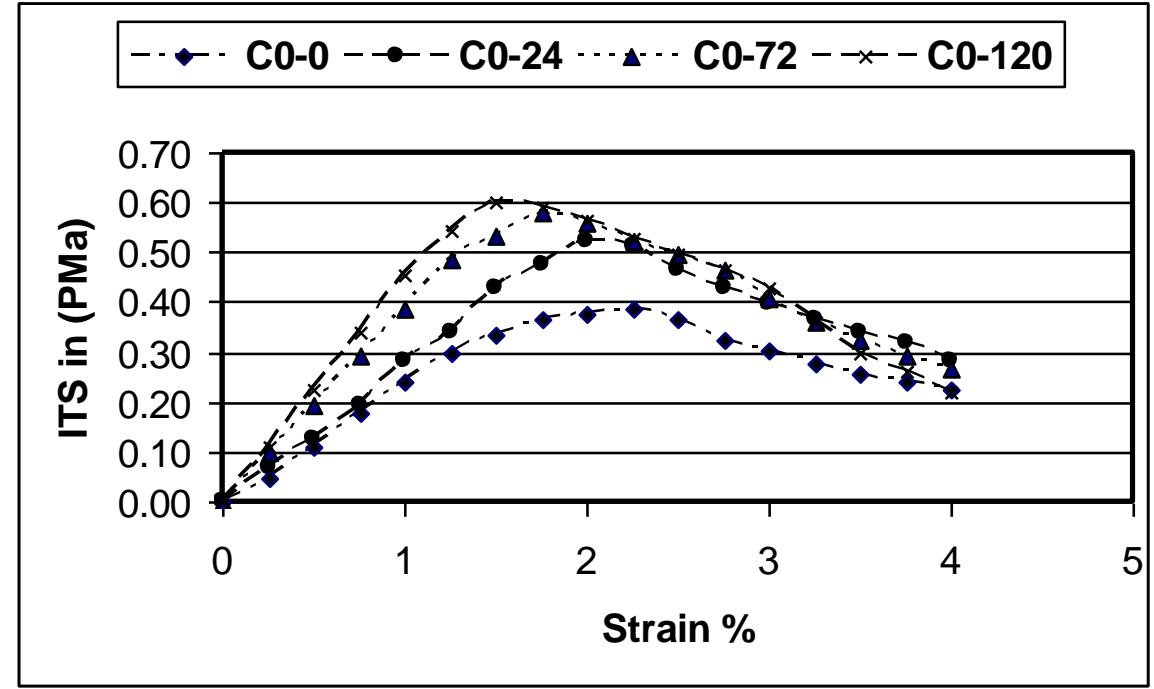

Fig. (9): Effect of ageing time in (hrs) on the Tensile Stress \& Strain relationship for long-term aged traditional mixtures

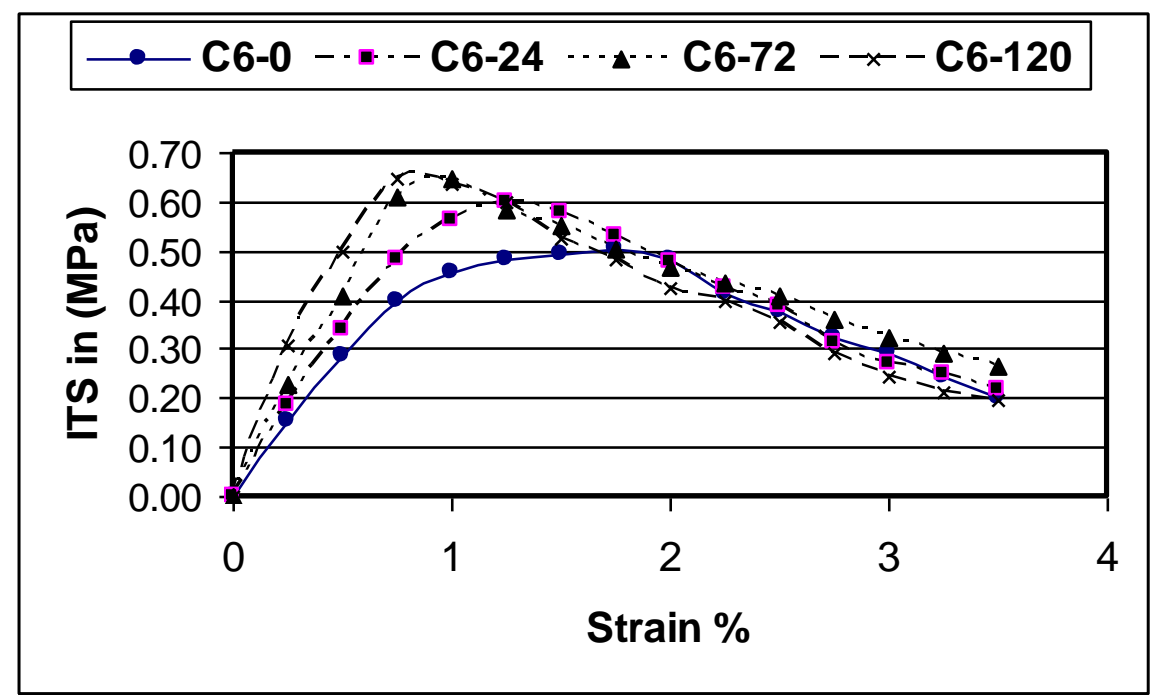


Fig. (10): Effect of ageing time in (hrs) on the Tensile Stress \& Strain relationship for short term aged followed by long term aged traditional mixtures

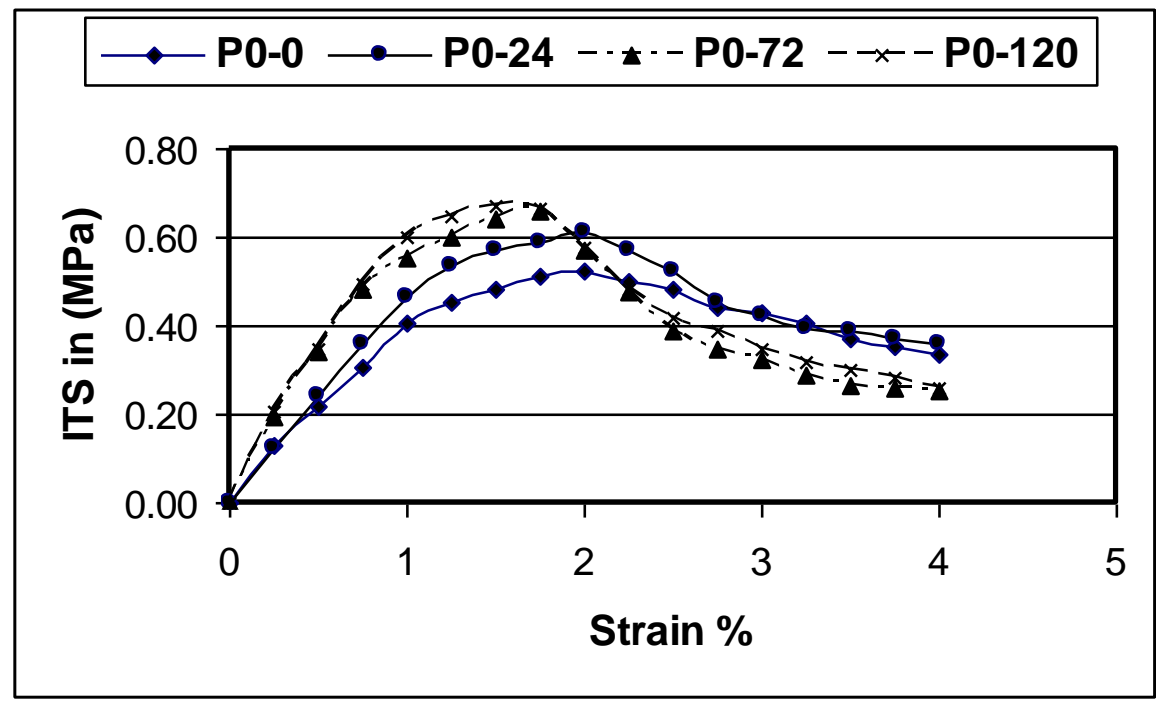

Fig. (11): Effect of ageing time in (hrs) on the Tensile Stress \& Strain relationship for Long-term aged plastiphalt mixtures

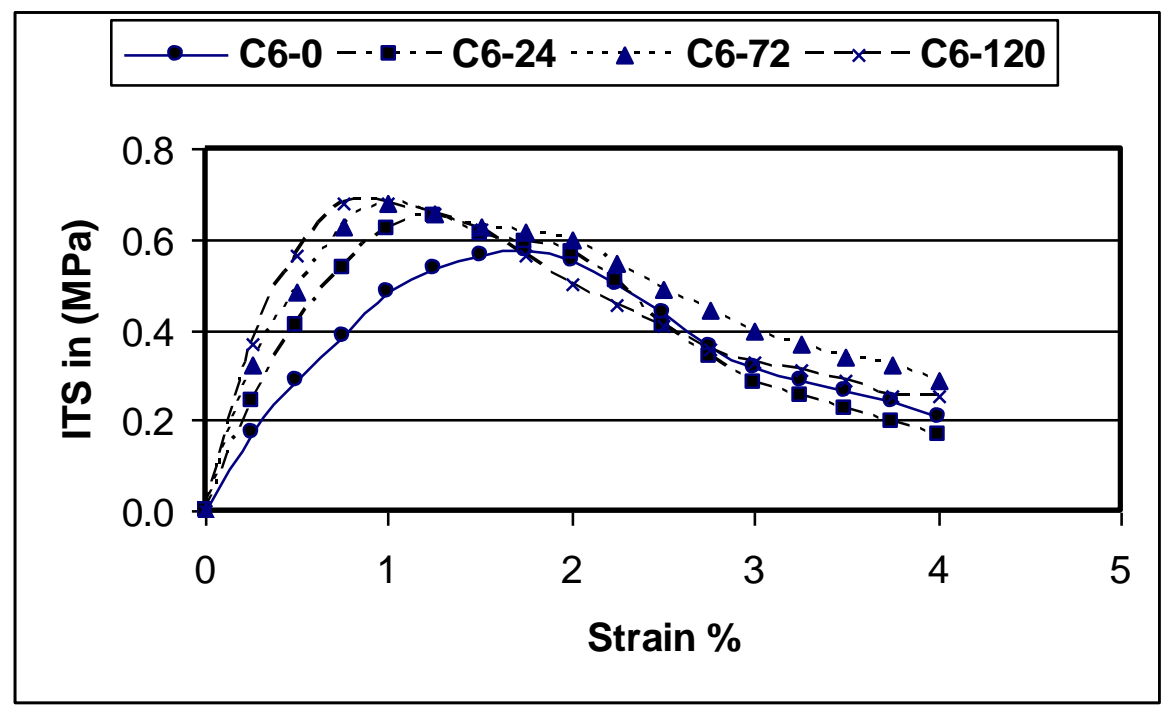

Fig. (12): Effect of ageing time in (hrs) on the Tensile Stress \& Strain relationship for short term aged followed by long term aged plastiphalt mixtures

It is found that the value of ITSR values for polypropylene treated composite mixtures had higher value (averaged $96 \%$ ) than the traditional mixtures (averaged 76 $\%)$. This indicates that the polypropylene treated composite mixtures had higher resistance of water susceptibility. This is may be attributed to that the polypropylene prime-coated aggregates would be highly hydrophobic, and much affinitive to asphalt 
binder, which would be critical for improving moisture susceptibility. Fig.(13) Summarizes the comparisons of laboratory performance between the Polypropylene treated composite and traditional mixtures. In Table (11), the performance improvements of the composite mixture were quantified in terms of percent improvement to the traditional mixture.

Table (11): Tensile strength ratio (TSR) for moisture susceptibility

\begin{tabular}{||c|c|c||}
\hline MIXTURE TYPE & $\begin{array}{c}\text { PLASTIPHALT } \\
\text { MIXTURE }\end{array}$ & $\begin{array}{c}\text { TRADITIONAL } \\
\text { MIXTURE }\end{array}$ \\
\hline dry ITS & $0.53 \mathrm{MPa}$ & $0.38 \mathrm{MPa}$ \\
\hline Conditioning Specimens ITS & $0.51 \mathrm{MPa}$ & $0.29 \mathrm{MPa}$ \\
\hline ITSR & $96 \%$ & $76 \%$ \\
\hline
\end{tabular}

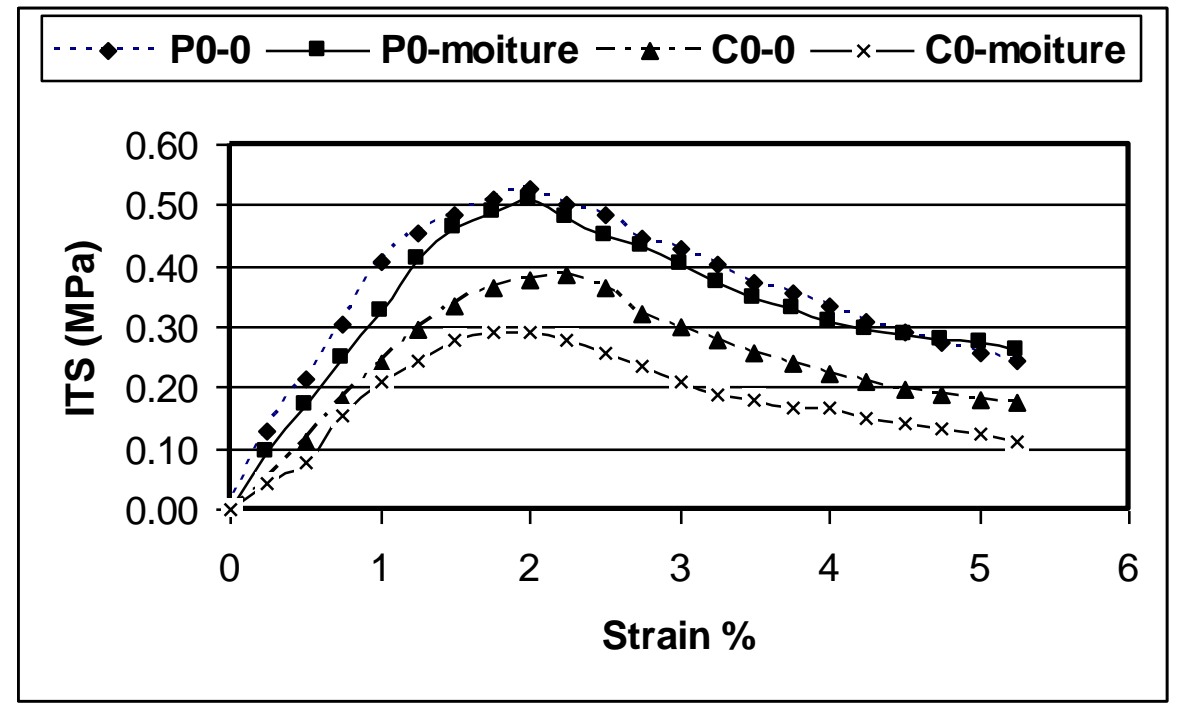

Fig. (13): Effect of moisture damage on ITS \& strain relationship for traditional and plastiphalt mixtures

\subsection{Unconfined Compression Strength Results.}

The unconfined compressive strength test was performed to determine. A compression load is applied on the circular face of the circular specimens. The load is increased until failure occurs. The average unconfined compressive strength for various mixtures is calculated based on Equation (4) and listed in Table (12). Fig (14) clear that polypropylene treated composite mixtures (C0) has the satisfactory results of compression strength (averaging $4.91 \mathrm{MPa}$ ) which was about 0.43 higher than that of traditional asphalt mixtures (averaging $3.44 \mathrm{MPa}$ ). This may be attributed to that the polypropylene has higher compressive strength value which increases the cohesive and 
adhesive strength of the asphalt pavement mixtures.

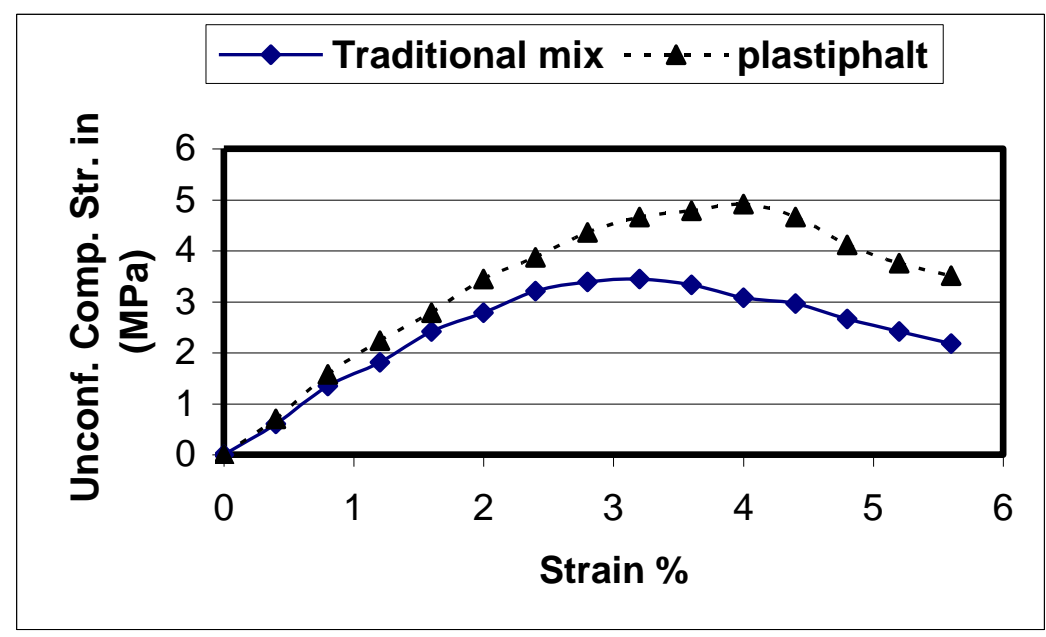

Fig. (14): Compression stress \& strain relationship for traditional and plastiphalt mixtures.

\subsubsection{Short-term and Long-term Ageing}

A relative influence of both short-term ageing (C6), and long-term ageing $\left(\mathrm{CO}_{24 \mathrm{hr}}, \mathrm{CO}_{72}\right.$ $\left.\mathrm{hr}, \mathrm{C}_{120 \mathrm{hr}}\right)$ and short term ageing followed by long-term ageing process $\left(\mathrm{C}_{24 \mathrm{hr}}, \mathrm{C6}_{72} \mathrm{hr}\right.$ , $\mathrm{C}_{120 \mathrm{hr}}$ ) for the traditional and plastiphalt mixtures considering the unconfined compressive strength values for different are presented. The results have been calculated to observe the change in unconfined compressive strength values for different samples. The results show that as expected, the relative effect of short-term conditioning is relatively higher compared to long-term ageing. It is also interesting to note that the ageing prosses for both short and long term ageing, the increment of hardening of plastiphalt mixtures is relatively lower than of traditional mixtures.

Tables (12 and 13) present the results from unconfined compressive strength and strains values respectively. The polypropylene treated composite mixtures had higher value of unconfined compressive strength than that for traditional mixtures with about $23 \%$ only, while the corresponding strain of the composite mixtures is relatively high with about $33 \%$ compared with that of traditional one [ ageing $\left(\mathrm{C6}_{120 \mathrm{hr}}\right)$ ]. This indicated good performance and less in hardening value of treated asphalt mixture than the traditional one.

The actual fracture resistance depends on the value of ultimate stress and corresponding strain values. The stress and strain curves shown in Figs. (14, 15, 16, and 17) it is clear that the polypropylene treated composite mixtures had both higher pre-peak and post-peak strain than the traditional mixture, which could be interpreted as the higher fracture resistance to crack propagation. This may be due to that the Polypropylene layer may have compensated the hardening of bitumen due to combined influence of polypropylene-bitumen layers interaction. 
Table (12): Unconfined compression stress for short and long-term aged traditional and plastiphalt mixtures.

\begin{tabular}{||c|c|c|c|l|l|l|l|l||}
\hline \hline \multirow{3}{*}{$\begin{array}{c}\text { Mixture } \\
\text { type }\end{array}$} & \multicolumn{7}{|c||}{ Average values of unconfind compretion stress in MPa } \\
\cline { 2 - 9 } & \multicolumn{2}{|c|}{ Short term } & \multicolumn{6}{|c||}{ Long term } \\
\cline { 2 - 9 } & $\mathrm{C} 0$ & $\mathrm{C} 6$ & $\mathrm{C}_{24} \mathrm{hr}$ & $\mathrm{C}_{72} \mathrm{hr}$ & $\mathrm{C}_{120} \mathrm{hr}$ & $\mathrm{C}_{24} \mathrm{hr}$ & $\mathrm{C}_{72} \mathrm{hr}$ & $\mathrm{C}_{120} \mathrm{hr}$ \\
\hline Traditional & 3.44 & 4.15 & 3.84 & 5.10 & 5.65 & 4.95 & 6.35 & 6.65 \\
\hline plastiphalt & 4.91 & 5.52 & 5.33 & 6.43 & 6.65 & 6.15 & 7.75 & 8.20 \\
\hline \hline
\end{tabular}

Table (13): \% age of strain at maximum unconfined compression stress for short and long-term aged for traditional and plastiphalt mixtures.

\begin{tabular}{||c|c|c|c|c|l|l|l|l||}
\hline \hline \multirow{3}{*}{$\begin{array}{c}\text { Mixture } \\
\text { type }\end{array}$} & \multicolumn{6}{|c||}{ Average values of \% age of train at maximum unconfind compression } \\
& \multicolumn{9}{|c||}{ stress } \\
\cline { 2 - 9 } & Short term & \multicolumn{7}{|c||}{ Long term } \\
\cline { 2 - 9 } & $\mathrm{C} 0$ & $\mathrm{C} 6$ & $\mathrm{C}_{24} \mathrm{hr}$ & $\mathrm{C}_{72} \mathrm{hr}$ & $\mathrm{C}_{120} \mathrm{hr}$ & $\mathrm{C}_{24} \mathrm{hr}$ & $\mathrm{C}_{72} \mathrm{hr}$ & $\mathrm{C}_{120} \mathrm{hr}$ \\
\hline traditional & 2.8 & 2.4 & 2.4 & 2.0 & 1.6 & 2 & 1.6 & 1.2 \\
\hline plastiphalt & 3.6 & 2.8 & 2.8 & 2.4 & 2.0 & 2.4 & 2.0 & 1.6 \\
\hline \hline
\end{tabular}

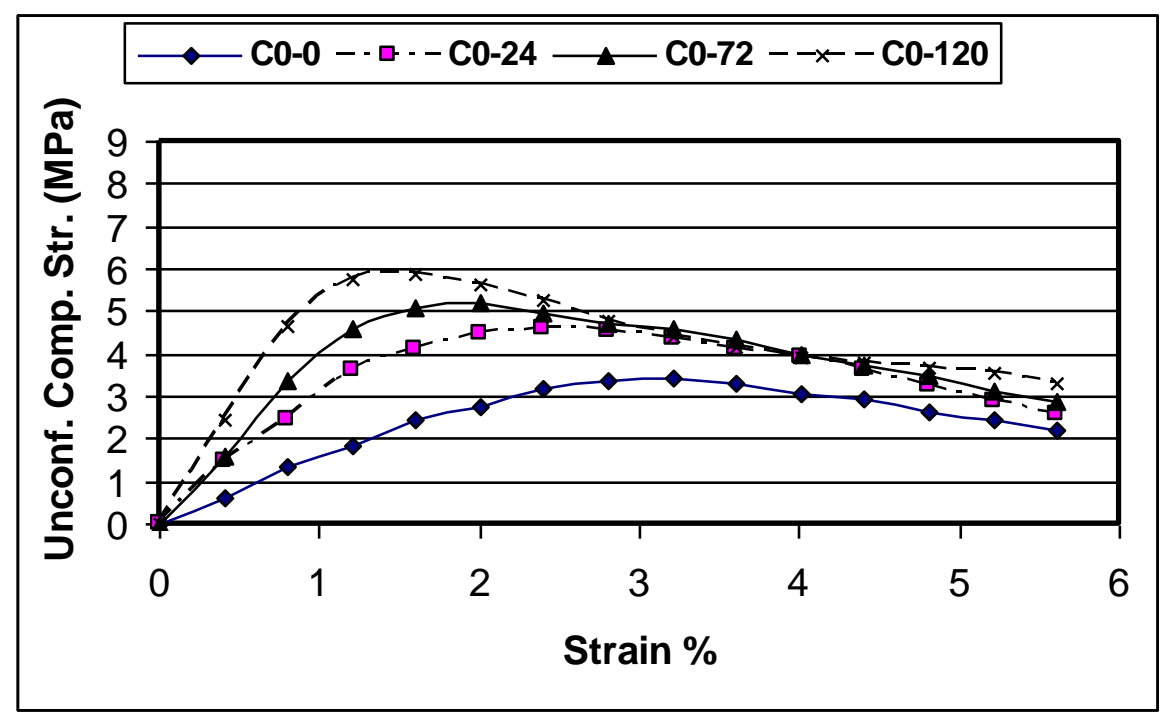

Fig. (14): Effect of ageing time in (hrs) on the Compression Stress \& Strain relationship for long-term aged traditional mixtures 


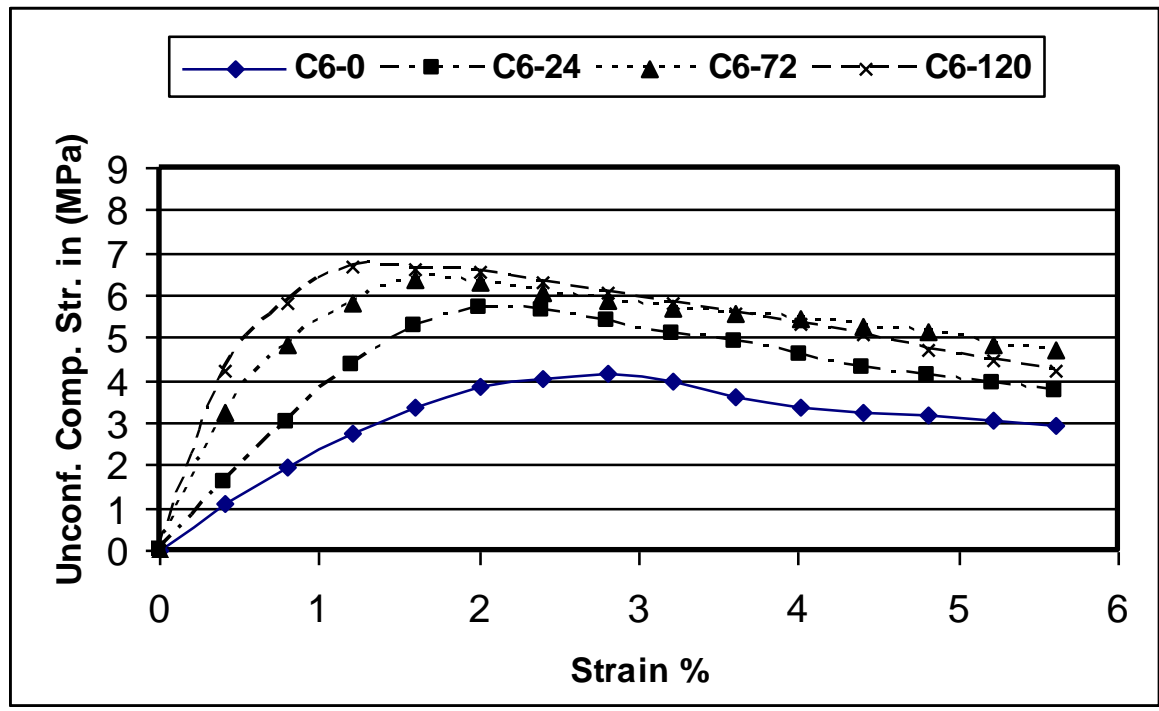

Fig.(15):Effect of ageing time in (hrs) on the Compression Stress \& Strain relationship for short term aged followed by long term aged traditional mixtures

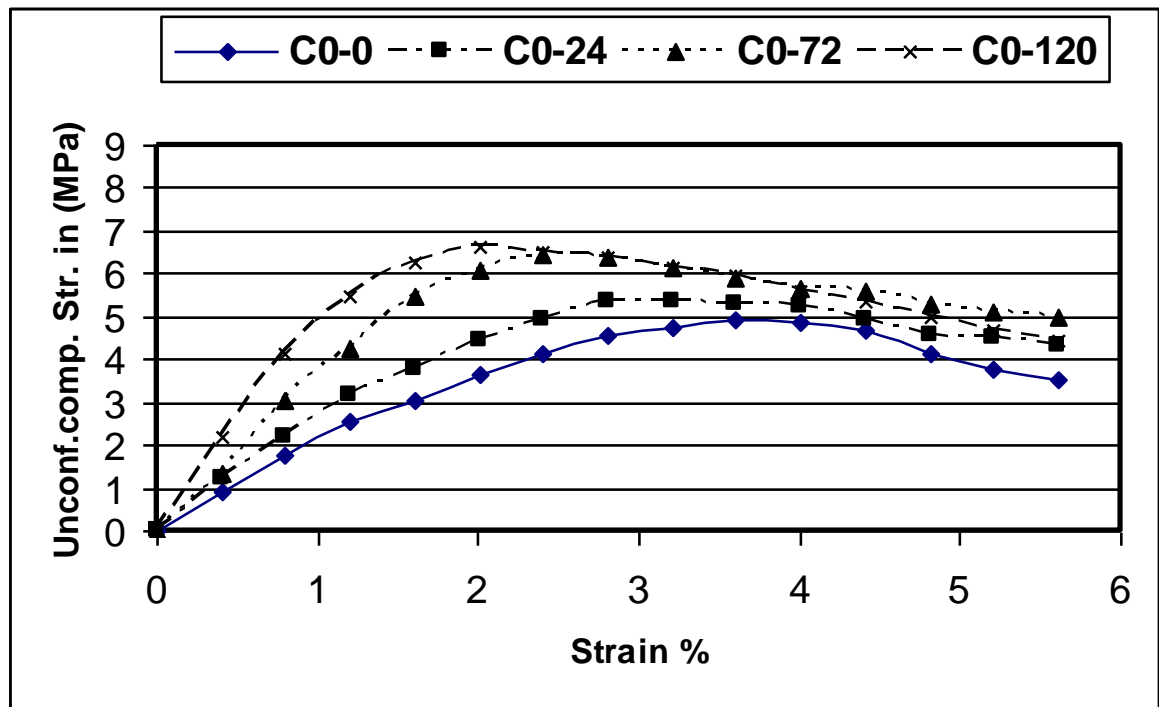

Fig. (16): Effect of ageing time in (hrs) on the Compression Stress \& Strain relationship for long-term aged plastiphalt mixtures 


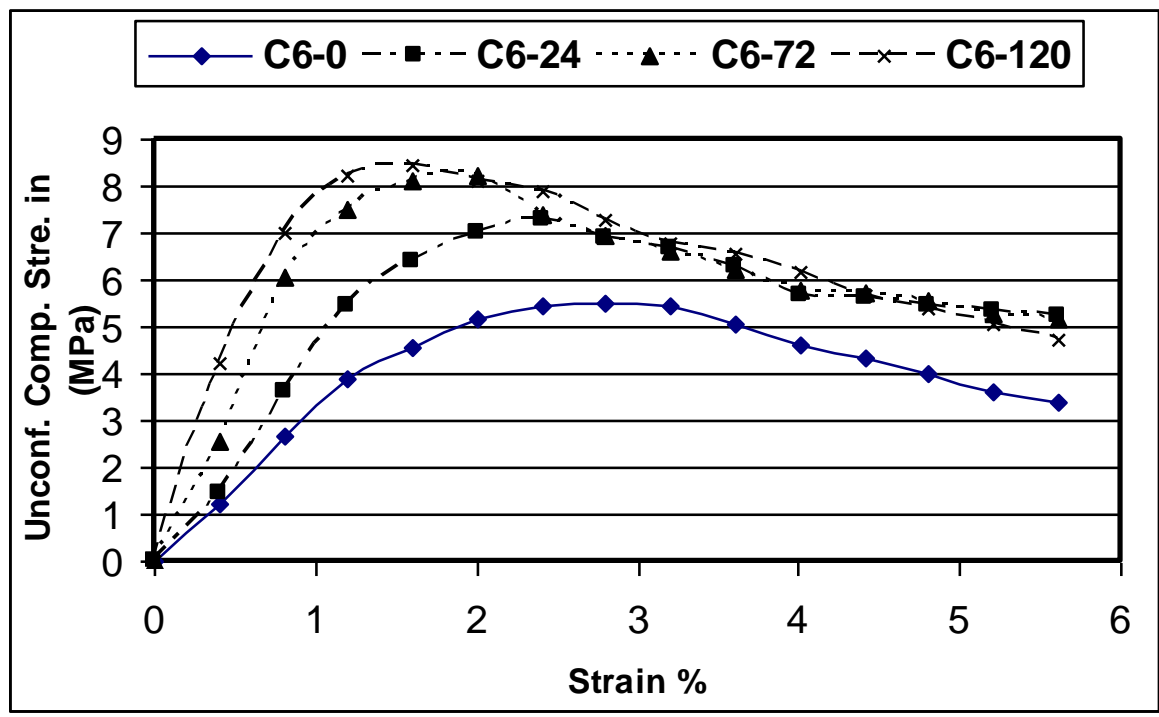

Fig. (17): Effect of ageing time in (hrs) on the Compression Stress \& Strain relationship for short term aged followed by long term aged plastiphalt mixtures

\section{SUMMARY AND CONCLUSIONS}

This paper presents a novel idea for using a polypropylene (PP) to mitigate the stress and strain concentration between aggregate surface and bitumen layer by introducing it as an intermediate layer between aggregate and asphalt binder in (HMA) mixture. A study has been conducted to investigate the new utilization of polypropylene (PP) to form three-layered composite structure into (HMA) mixtures to enhance the performance of asphalt pavement. The short term and long-term ageing performance of the polypropylene treated asphalt mixtures have been studied and compared to the performance of the traditional ones. Moisture damage effect through subjecting the samples to vacuum water pressure is also conducted.

The following conclusion can be drawn out from these investigations:

1- Laboratory experiments indicated improved mixture performance in Marshall stability, Marshal Quotient, Indirect Tensile Strength, and Unconfined Compressive Strength of the polypropylene (PP) composite asphalt mixture. This may be due to the high adhesion between polypropylene layer and aggregate surface and also the best merging between bitumen material and polypropylene layer.

2- The results show that, the rate of short-term ageing is relatively significant higher compared to long-term ageing, which points towards the importance of the mixing, transportation and laying period on mixture's ageing.

3- Its found that the hardening rate of the asphalt concrete materials increases dramatically during the early life of road pavements, so the mechanical properties of asphalt pavement within the early age (suggested first year) must be predicted and considered in asphalt pavement design. 
4- The rate of hardening of polypropylene treated asphalt mixtures is relatively less than that for traditional asphalt mixtures considering short and long term ageing process. This may be attributed to the polypropylene layer has minimize the effect of ageing of bitumen due to its plastic properties and its higher resistance for temperature compared with bitumen material.

5- Compared with traditional mixture, the polypropylene treated composite mixtures had higher resistance of water susceptibility, where the ITSR values for polypropylene treated composite mixtures had higher value (averaged $96 \%$ ) than the traditional mixtures (averaged $76 \%$ ). This is may be attributed to that the polypropylene prime-coated aggregates would be highly hydrophobic, and much affinitive to asphalt binder, which would be critical for improving moisture susceptibility.

6- Analysis shows that the polypropylene treated composite mixtures have excellent crack resistance performance compared with traditional one, that is because plastiphalt needs more energy than that of traditional mixtures when it reaches material failure situation.

7- Before widely using polypropylene as a third layer in asphalt concrete mixture, pilot projects should be initiated and adequate provisions should be provided for the proper handling of the material.

\section{REFERENCES.}

1- Li G, Zhao Y, Pang SS. "Micro Mechanical Modeling Of Polymer Modified Asphalt At Low Temperatures". J Elastomers Plast 283-301. 2000.

2- Li G, Stubble.eld MA, Garrick G, Eggers J, Abadie C, Huang B. "Development Of Waste Tire Modified Concrete". Cem Concr Res 34 (12) :2283-9, 2004.

3- Curtis, C.W., K. Ensley, and J.A. Epps. "Fundamental Properties Of AsphaltAggregate Interactions Including Adhesion And Absorption", Final report SHRP A-341, Strategic Highway Research Program, National Research Council, Washington, D.C., 2001.

4- Brij D. Shah, " Evaluation Of Moisture Damage Within Asphalt Concrete Mixes" A Thesis Submitted to Texas A\&M University in partial fulfillment of the requirements for the degree of MASTER OF SCIENCE, August 2003.

5- Petersen JC. "Asphalt Aging Dual Oxidation Mechanism And Its Interrelationship With Asphalt Composition And Oxidative Age Hardening". In Asphalt mixture components. Transportation research. Record. Vol. 1638. pp. 47-55, 1998.

6- Brown, S.F., Gibb, J.M., Read, J.M., Scholz, T.V., Cooper, K.E., 1995. "Design And Testing Of Bituminous Material". Volume 2 : Research Report, Submitted to Dot/Epsrc Link Programme on Transport Infrastructure and Operations, 1995.

7- Scholz, T.V., "Durability of Paving Mixtures". PhD Thesis, School of Civil Engineering, The University of Nottingham.1955.

8- Scholz, T.V. and Brown, S. F., "Factors Affecting The Durability Of Bituminous Paving Mixtures". Performance and Durability of Bituminous 
Materials", Proceeding of European Symposium, University of Leeds, pp 173190. 1996.

9- American Association of State Highways and Transportation Officials., "Practice For Short And Long Term Ageing Of Hot Mix Asphalt". AASHTO Designation PP2. 1994.

10- Brown, S.F., Gibb, J.M., Read, J.M., Scholz, T.V., Cooper, K.E., "Design And Testing Of Bituminous Material". Volume 2: Research Report, Submitted to DOT/EPSRC LINK Programme on Transport Infrastructure and Operations, 1995.

11- Tandon V, Vemuri N, Nazarian S. "Evaluation Of Environmental Conditioning System For Predicting Moisture Susceptibility Of Asphalt Concrete Mixtures", Transportation Research Board, 75th Annual Meeting, Washington DC, 1996.

12- Baoshan Huang $a,{ }^{*}$, Guoqiang Li b, Xiang Shu a "Investigation Into ThreeLayered HMA Mixtures Composites" : Part B 37 679-690, 2006.

13- N. Kulolu, "Effect Of Astragalus On Characteristics Of Asphalt Concrete". Journal of Materials in Civil Engineering p. 283, 11 4, 1999.

14- Shell Bitumen Handbook, p. $260,1991$.

15- Hot Mix Asphalt Materials, Mixture Design and Construction, National Center for Asphalt Technology, p. 225. 1991.

16- L.E. Chavez-Valencia, A. Manzano-Ramirez, Luna-Barcenas and E. AlonsoGuzman, "Modeling Of The Performance Of Asphalt Pavement Using Response Surface Methodology", Building and Environment pp. 1140-1149, 2005.

17- E. Ray Brown, Prithvi S. Kandhal, and Jingna Zhang,"Performance Testing For Hot Mix Asphalt", NCAT Report 01-05, November 2001

18- Lottman RP, White LJ, Frith DJ. "Methods Of Predicting And Traditionalling Moisture Damage In Asphalt Concrete". Transport Res Rec;1171:1-11, 1988

19- Zeng M, Ksaibati K. "Evaluation Of Moisture Susceptibility Of Asphalt Mixtures Containing Bottom Ash". The annual meeting of Transportation Research Board (CDROM): Washington (DC, USA); 2002.

20- Parker, F., and F. Gharaybeh. "Evaluation Of Indirect Tensile Tests For Assessing Stripping Of Alabama Asphalt Concrete Mixtures." Transportation Research Board, Transportation Research Record 1115, 1987.

21- E. Ray Brown, Prithvi S. Kandhal, and Jingna Zhang. "Performance Testing For Hot Mix Asphalt" NCAT Report 01-05, November 2001.

22- "Recommendation For The Performance Of Unconfined Static Creep Test In Asphalt Specimens." Proceedings of the International Symposium on Plastic Deformability of Bituminous Mixes, pp 335-359, Zurich, 1977

23- Kamil E. Kaloush, Matthew W. Witczak, "Simple Performance Test For Permanent Deformation Of Asphalt Mixtures" Presented at the 81st Annual Transportation Research Board Meeting, Washington D.C., January 2002.

24- Cai SW, Cai M. "Concrete Damage And Crack". Beijing, China: Transportation Publishing House; 1999. 


\section{الخواص الميكانيكية للخلطات الأسفلتية المحسنة والمعرضة للتقادم}

\section{على المدى القصير والمدى الطويل}

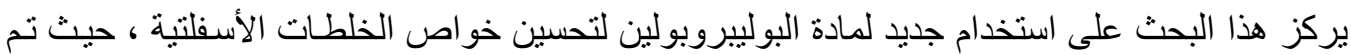

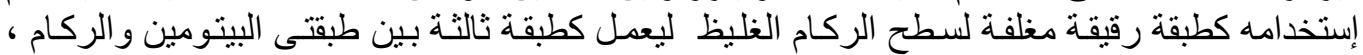

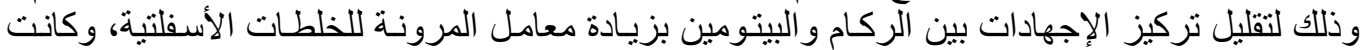

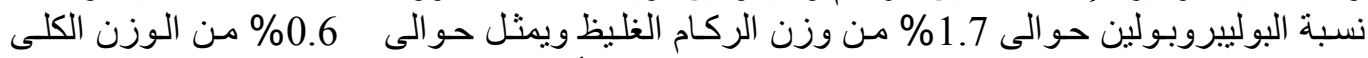

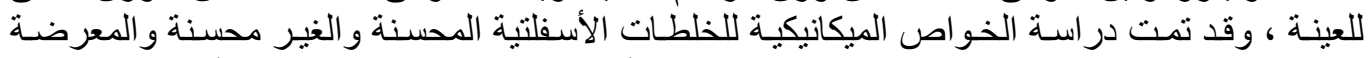

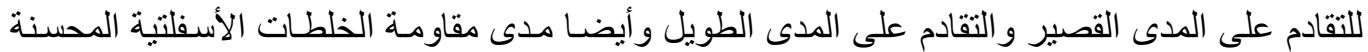

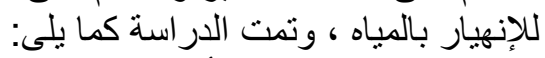

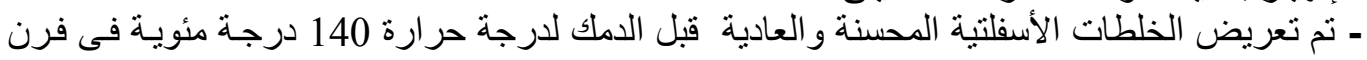

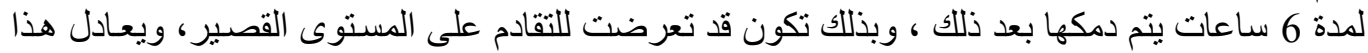

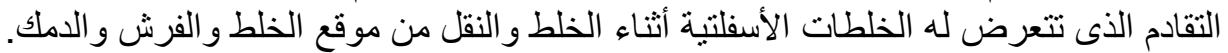

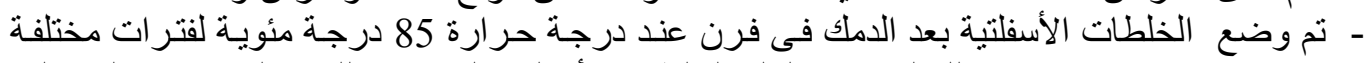

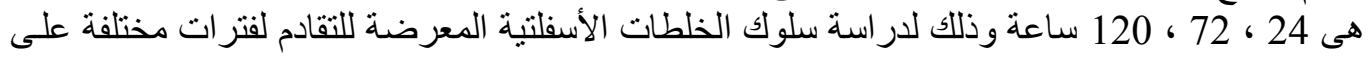

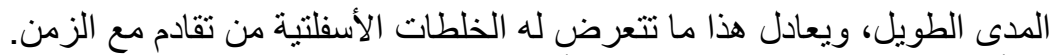

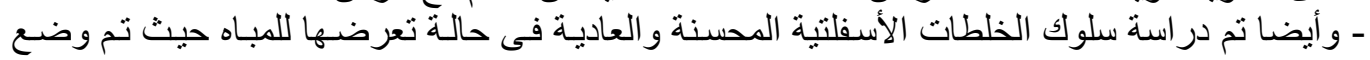

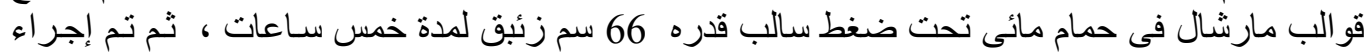

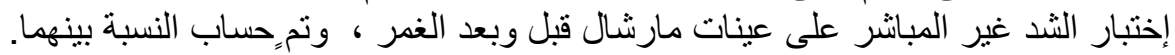

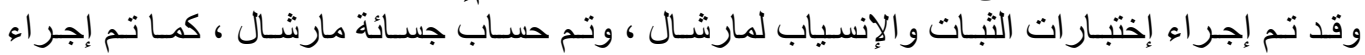

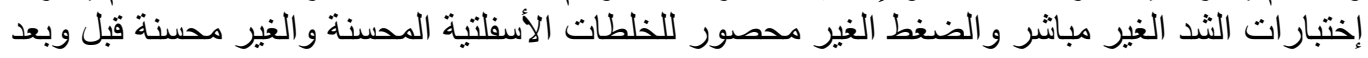

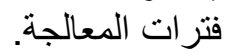

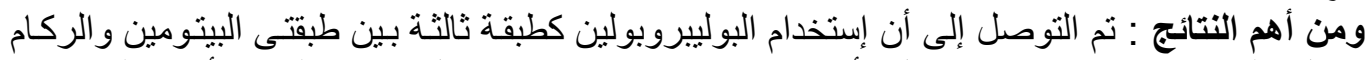

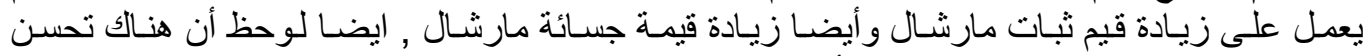
و واضح للخو اص الميكانيكية للخلطات الأسفلتية المحسنة.

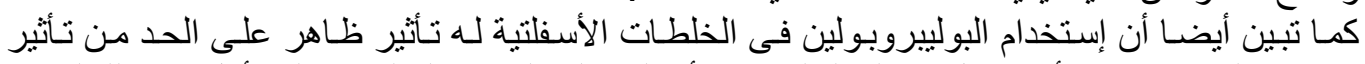

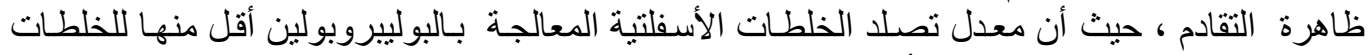

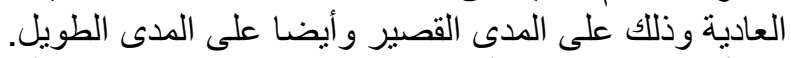

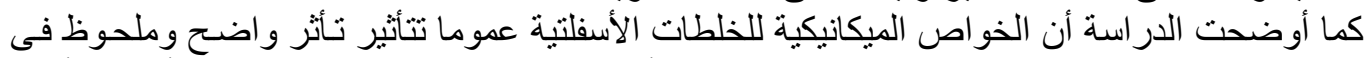

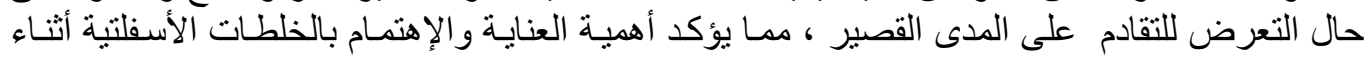

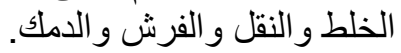

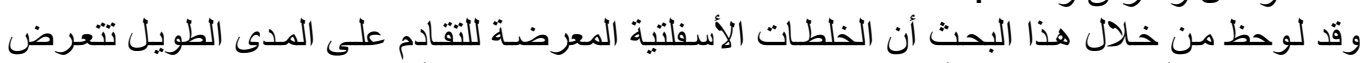

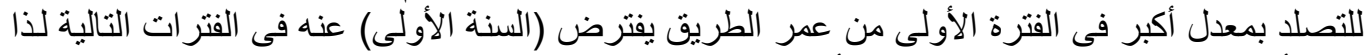

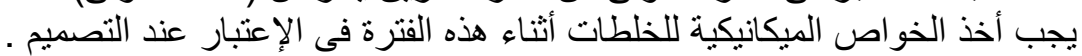

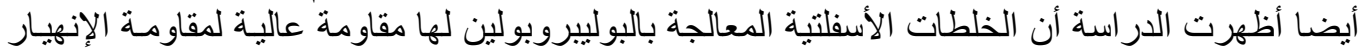
بلمبياه عن الخلطات العادية.

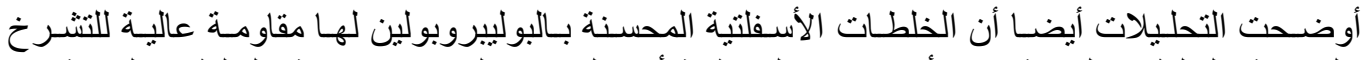
بالمقارنة بالخلطات العادية جيث أنها تحتاج إلى طاقة أكبر لحدوث اللإنهيار مقارنة بالخلطات العادية العادية. 